\title{
Article \\ Simultaneous Quantification of Propylthiouracil and Its $N-\beta-D$ Glucuronide by HPLC-MS/MS: Application to a Metabolic Study
}

\author{
Min Li ${ }^{1,+}$, Qingfeng He ${ }^{1,+}{ }^{\oplus}$, Li Yao ${ }^{1}$, Xiaofeng Wang ${ }^{1}$, Zhijia Tang ${ }^{1}{ }^{\mathbb{D}}$, Xiao Zhu ${ }^{1}$, Hai-Shu Lin ${ }^{2, *} \mathbb{1}$ and \\ Xiaoqiang Xiang ${ }^{1, *(1)}$ \\ 1 Department of Clinical Pharmacy and Pharmacy Administration, School of Pharmacy, Fudan University, \\ Shanghai 201203, China; 19211030067@fudan.edu.cn (M.L.); qf_he@fudan.edu.cn (Q.H.);

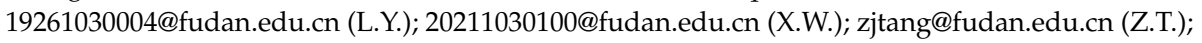 \\ xiaozhu@fudan.edu.cn (X.Z.) \\ 2 College of Pharmacy, Shenzhen Technology University, Shenzhen 518118, China \\ * Correspondence: linhaishu@sztu.edu.cn (H.-S.L.); xiangxq@fudan.edu.cn (X.X.); Tel.: +86-21-51980024 (X.X.) \\ + Authors contributed equally to this work.
}

check for updates

Citation: Li, M.; He, Q.; Yao, L.; Wang, X.; Tang, Z.; Zhu, X.; Lin, H.-S.; Xiang, X. Simultaneous

Quantification of Propylthiouracil and Its $N-\beta-D$ Glucuronide by HPLC-MS/MS: Application to a Metabolic Study. Pharmaceuticals 2021, 14, 1194. https://doi.org/10.3390/ ph14111194

Academic Editor: Angel Guerrero

Received: 25 October 2021

Accepted: 18 November 2021

Published: 20 November 2021

Publisher's Note: MDPI stays neutral with regard to jurisdictional claims in published maps and institutional affiliations.

Copyright: (c) 2021 by the authors. Licensee MDPI, Basel, Switzerland. This article is an open access article distributed under the terms and conditions of the Creative Commons Attribution (CC BY) license (https:// creativecommons.org/licenses/by/ $4.0 /)$.

\begin{abstract}
Propylthiouracil (PTU) is commonly prescribed for the management of hyperthyroidism and thyrotoxicosis. Although the exact mechanism of action is not fully understood, PTU is associated with hepatoxicity in pediatric population. Glucuronidation mediated by uridine $5^{\prime}$-diphosphoglucuronosyltransferases (UGTs), which possess age-dependent expression, has been proposed as an important metabolic pathway of PTU. To further examine the metabolism of PTU, a reliable HPLCMS/MS method for the simultaneous quantification of PTU and its N- $\beta$-D glucuronide (PTU-GLU) was developed and validated. The chromatographic separation was achieved on a ZORBAX ExtendC18 column $(2.1 \times 50 \mathrm{~mm}, 1.8 \mu \mathrm{m})$ through gradient delivery of a mixture of formic acid, methanol and acetonitrile. The electrospray ionization (ESI) was operated in its negative ion mode while PTU and PTU-GLU were detected by multiple reaction monitoring (MRM). This analytical method displayed excellent linearity, sensitivity, accuracy, precision, recovery and stability while its matrix effect and carry-over were insignificant. Subsequently, the in vitro metabolism of PTU was assessed and UGT1A9 was identified as an important UGT isoform responsible for the glucuronidation of PTU. The information obtained from this study will facilitate future mechanistic investigation on the hepatoxicity of PTU and may optimize its clinical application.
\end{abstract}

Keywords: propylthiouracil; propylthiouracil glucuronide; in vitro; human liver microsomes; UGT1A9; HPLC-MS/MS

\section{Introduction}

Propylthiouracil (PTU) is a thionamide medication commonly prescribed for the management of Graves' disease and hyperthyroidism ever since the 1940s [1]. Besides inhibiting the synthesis of thyroid hormones by blocking the iodine oxidation in the thyroid gland, PTU also interrupts the conversion of tetraiodothyronine to triiodothyronine in peripheral tissues [2]. In comparison to methimazole [3,4], which is frequently used as a first-line therapeutic agent, PTU is preferred in the first trimester of pregnancy or treating thyroid storm/thyrotoxicosis [5]. Although PTU has good safety profiles in adult population with a relatively low incidence rate of hepatoxicity $(1$ in 10,000), an increased risk of acute liver failure was reported in the pediatric population [6-8]. Therefore, the U.S. Food and Drug Administration (FDA) issued a black box warning in 2009, followed by similar actions from the European Medicines Agency and the United Kingdom Medicines and Healthcare Regulatory Agency in the same year. So far, the exact mechanism of action of PTU-induced hepatotoxicity remains unclear. 
PTU is commonly administered through the oral route and displays rapid absorption with an excellent bioavailability of $75 \%[9,10]$. Plasma protein binding of PTU is as high as $80-85 \%$. PTU is mainly eliminated by the liver through the formation of glucuronides or sulfates. Within $24 \mathrm{~h}$, around $35 \%$ of the dosed PTU is excreted as metabolite forms in urine [11]. So far, the role of the proposed intermediates in hepatoxicity is unclear. Reactive metabolites produced by myeloperoxidase in neutrophils might be responsible for agranulocytosis; however, the presence of such intermediates has not been observed in the liver [12]. PTU or its metabolites might also affect some intracellular targets, which consequently mediate hepatoxicity. Moreover, it was reported that glutathione transferase and glutathione peroxidase were inhibited in a concentration-dependent manner by PTU and its sulfated metabolites [13].

Glucuronidation, which is catalyzed by uridine $5^{\prime}$-diphospho-glucuronosyltransferases (UGTs) is generally considered as an effective pathway for the elimination of xenobiotics. Similar to many well-known drugs including morphine, propofol, and acetaminophen, PTU is subjected to conjugation with propylthiouracil N- $\beta-D$ glucuronide (PTU-GLU) as a metabolite [14,15]. Interestingly, UGT1A9/2B4 activities were found to be relatively low in infants (0.5-2 years) in comparison to adults [16-19]. This is probably due to lower transcription of UGT1A9/2B4, which had been observed in pediatric livers [18]. Insufficient UGTs activities may hinder the clearance of PTU, resulting in hepatotoxicity. Age-dependent activities of UGTs appear to be a reasonable explanation of the difference in safety profile between adults and infants [20-22]. Clearly, it is of scientific interest to identify the specific UGTs isoform that is responsible for the glucuronidation of PTU.

An accurate bioanalytical method for the quantification of PTU and PTU-GLU will enable further investigation on this topic. So far, several chromatographic methods including HPLC with ultraviolet (UV) [23], HPLC with Mass Spectrometry (MS) [24] and HPLC with iodine-azide reaction as detection systems [25] have been attempted. However, neither a validated analytical method for PTU-GLU nor a protocol for simultaneous quantification of PTU and PTU-GLU has been established.

In this study, a reliable HPLC-MS/MS method for the simultaneous quantification of propylthiouracil and its N- $\beta$-D glucuronide has been developed and validated. Glucuronidation of propylthiouracil has been subsequently examined in in vitro systems. The information obtained from this study will facilitate future mechanistic investigation on the hepatoxicity of PTU and may optimize its clinical application.

\section{Results and Discussion}

\subsection{HPLC-MS/MS Conditions and Method Optimization}

Through optimizing the instrumental parameters of mass spectrometry, we obtained sensitive and robust signals of the analytes. Methylthiouracil (MTU) is chosen as an internal standard (IS) due to its structural similarity to PTU. Full-scan and product ion scan were applied to identify the mass-spectra of PTU, its metabolite PTU-GLU and IS (Figure 1) in negative electrospray ionization (ESI) mode. During method optimization, it was observed that the strongest precursor ions $>$ product ions signals were $m / z 169.20>58.05,345.2>169.20$, and $141.0>58.00$ for PTU, PTU-GLU, and MTU, respectively (shown in Figure 1).

Chromatographic separation of analytes was achieved on a ZORBAX Extend-C18 column $(2.1 \times 50$ mm, $1.8 \mu \mathrm{m}$; Agilent Technologies, Waldbronn, Germany). PTU, PTUGLU, and MTU eluted at $1.66 \mathrm{~min}, 1.50 \mathrm{~min}, 1.40 \mathrm{~min}$, respectively with optimal peak shapes (Figure 2). The HPLC-MS/MS was controlled by the software of LabSolution and the experimental parameters were subsequently optimized while multiple reaction monitoring (MRM) was applied to measure the analytes.

The optimized HPLC-MS/MS parameters are listed in Table 1 and the proposed fragmentation pathway is illustrated in Figure 3. 

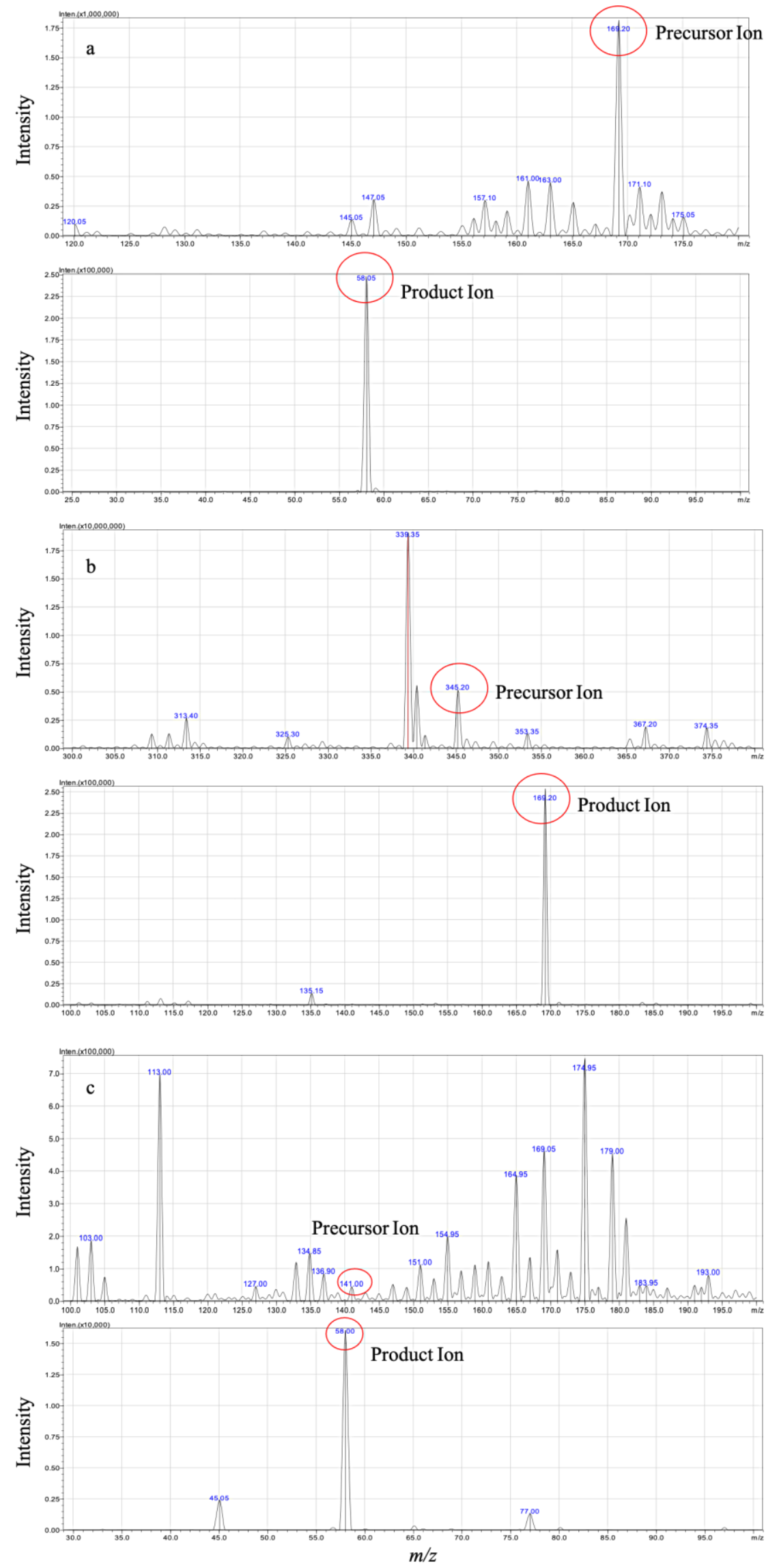

Figure 1. Mass spectra of PTU (a), PTU-GLU (b), and MTU (c) in ESI mode. 

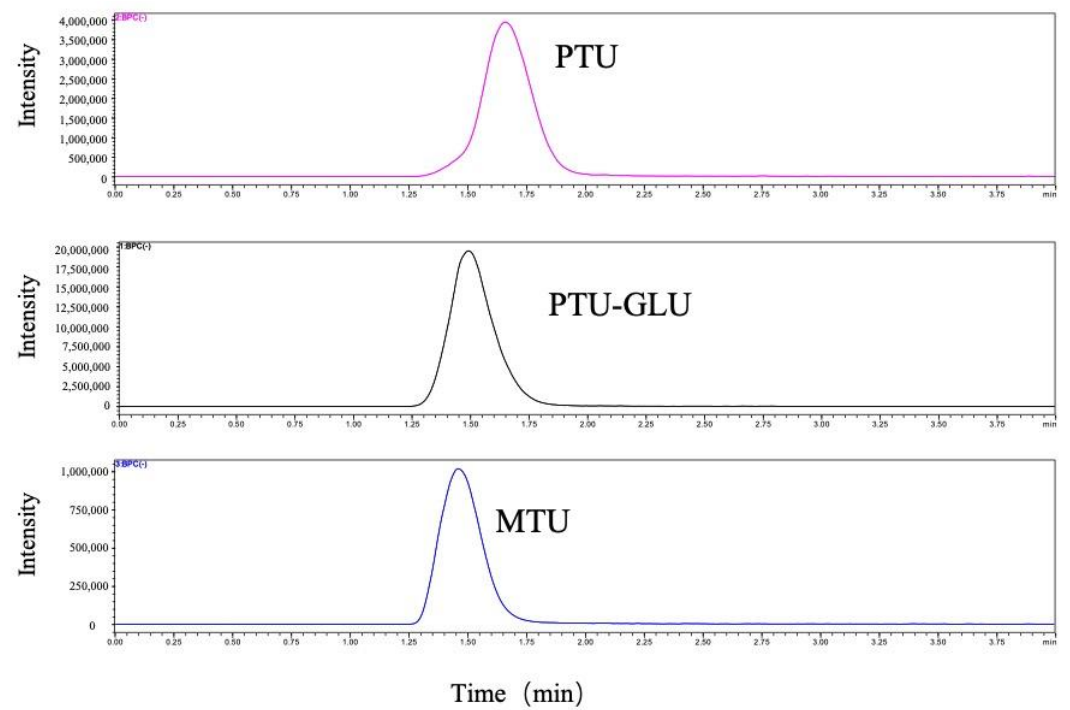

Figure 2. Representative MRM ion chromatograms of PTU, PTU-GLU and MTU.

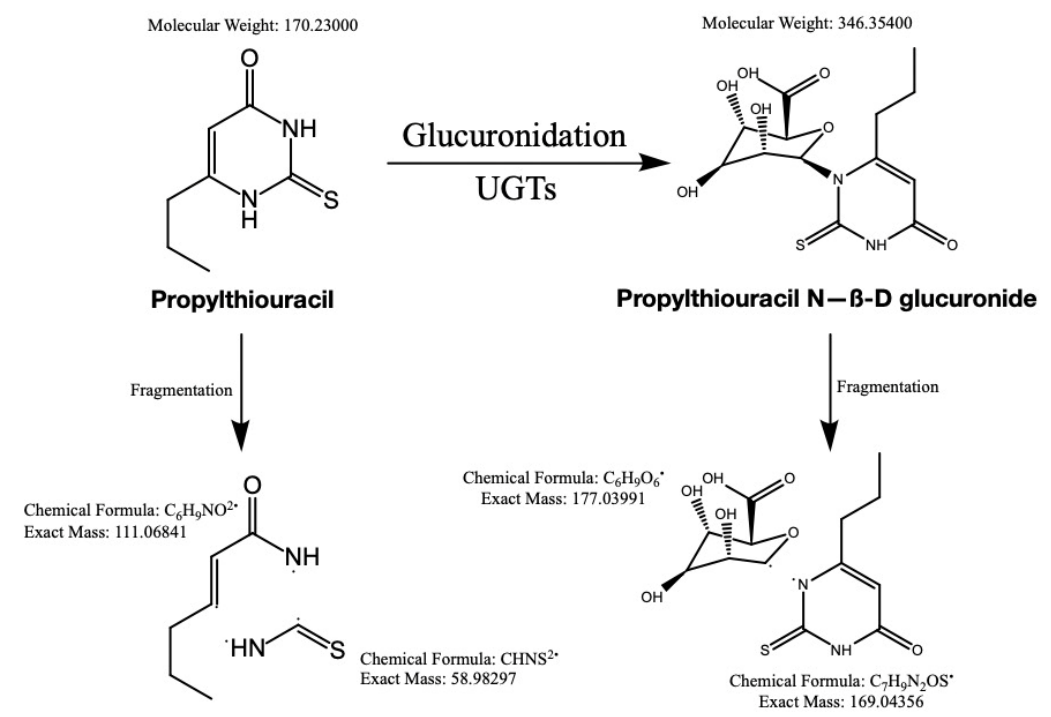

Figure 3. The structure of PTU and PTU-GLU, along with proposed fragmentation pathways.

Table 1. Summary of HPLC-MS/MS parameters.

\begin{tabular}{|c|c|c|c|}
\hline & PTU & PTU-GLU & MTU(IS) \\
\hline MRM Transition m/z (Q1-Q3) & $169.2>58.05$ & $345.2>169.2$ & $141.00>58.00$ \\
\hline MS Ionization & & ESI mode & \\
\hline Q1 (V) & 12.0 & 13.0 & 10.0 \\
\hline Q2 (V) & 22.0 & 14.0 & 22.0 \\
\hline $\mathrm{Q} 3(\mathrm{~V})$ & 20.0 & 17.0 & 19.0 \\
\hline Column & \multicolumn{3}{|c|}{ ZORBAX Extend-C18 column $(2.1 \times 50 \mathrm{~mm}, 1.8 \mu \mathrm{m})$} \\
\hline Column Temperature & \multicolumn{3}{|c|}{$35^{\circ} \mathrm{C}$} \\
\hline Run Time & \multicolumn{3}{|c|}{$4 \min$} \\
\hline Mobile Phase & \multicolumn{3}{|c|}{$\begin{array}{l}\text { Phase A: water }(0.1 \% \text { formic acid }) \\
\text { Phase B: methanol/acetonitrile }(0.1 \% \text { formic acid })(2: 1, v / v)\end{array}$} \\
\hline Flow & \multicolumn{3}{|c|}{$0.1 \mathrm{~mL} / \min (40: 60=\mathrm{A}: \mathrm{B})$} \\
\hline Injection Volume & \multicolumn{3}{|c|}{$1 \mu \mathrm{L}$} \\
\hline Retention Time & $1.66 \mathrm{~min}$ & $1.50 \mathrm{~min}$ & $1.40 \mathrm{~min}$ \\
\hline
\end{tabular}




\subsection{Assay Validation}

\subsubsection{Selectivity}

This bioanalytical method displayed excellent selectivity. No notable interference for PTU, PTU-GLU and IS was observed at lower limit of quantification (LLOQ) $(0.1 \mu \mathrm{M})$ in the presence of biological matrices such as human liver microsomes (HLMs) and human recombinant UGT1A9, and UGT inhibitor (magnolol). Representative chromatograms of HLMs/human recombinant UGT1A9 spiked with PTU, PTU-GLU and IS are shown in Figure 4.

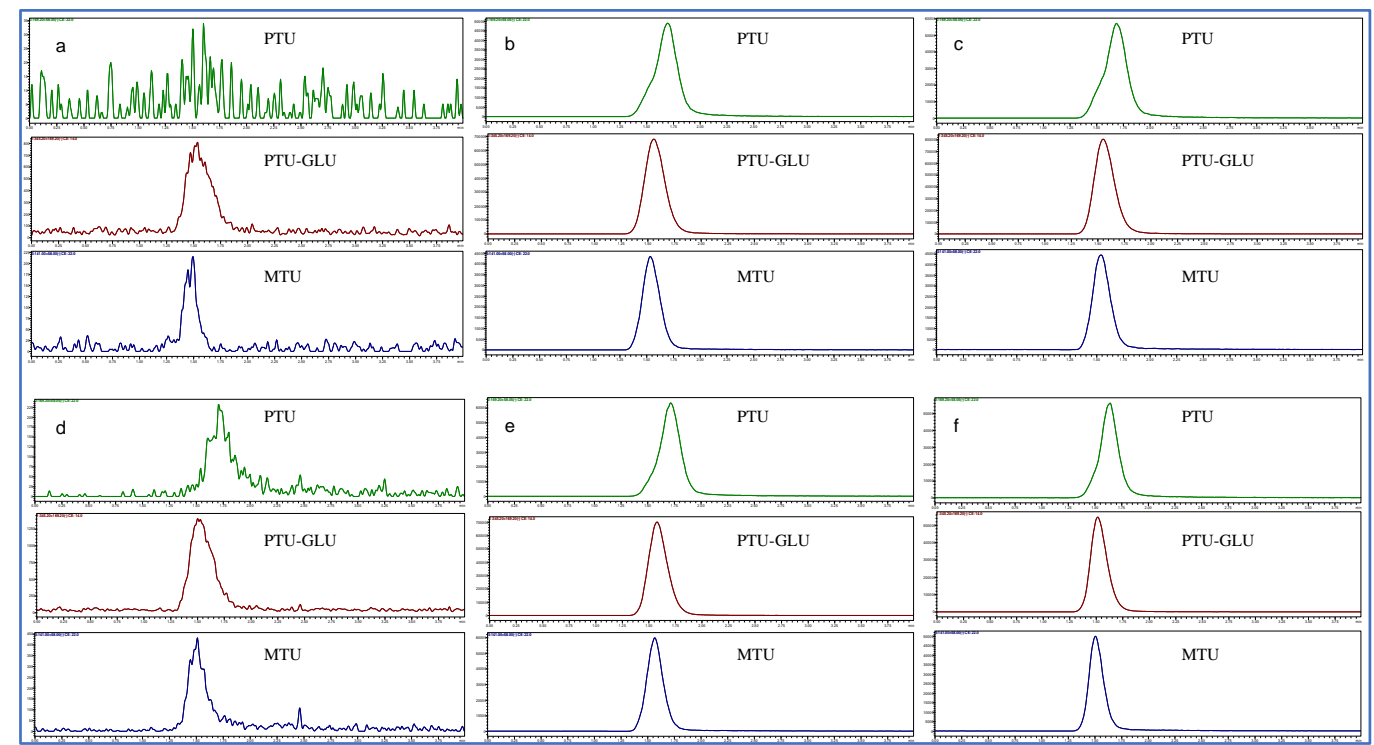

Figure 4. Representative chromatograms of HLMs and human recombinant UGT1A9 spiked with PTU (0.1 $\mu$ M), PTUGLU $(0.1 \mu \mathrm{M})$ and MTU (IS, $10 \mu \mathrm{M})$. (a) blank HLMs; (b) inactive HLMs spiked with PTU, PTU-GLU and IS; (c) inactive HLMs spiked with PTU, PTU-GLU, IS and UGT1A9 inhibitor magnolol (50 $\mu \mathrm{M})$; (d) blank human recombinant UGT1A9; (e) inactive human recombinant UGT1A9 with PTU, PTU-GLU and IS; (f) inactive human recombinant UGT1A9 spiked with PTU, PTU-GLU, IS and UGT1A9 inhibitor magnolol (50 $\mu \mathrm{M})$.

\subsubsection{Sensitivity}

The lower limit of quantitation (LLOQ) was established at $0.1 \mu \mathrm{M}$ for both analytes with acceptable accuracies and precision (data not shown).

\subsubsection{Calibration Curve and Linearity}

As shown in Figure 5, the calibration curves with the optimal fit were established over the concentration ranging from 0.1 to $50 \mu \mathrm{M}$ for PTU and PTU-GLU. Both $R^{2}$ values of the calibration curves were higher than 0.99 , indicating good linearity of the assay.

a

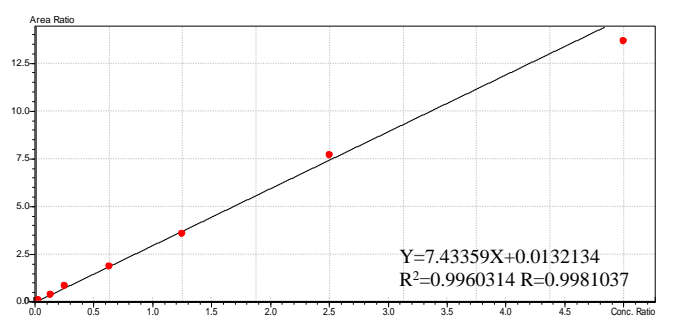

b

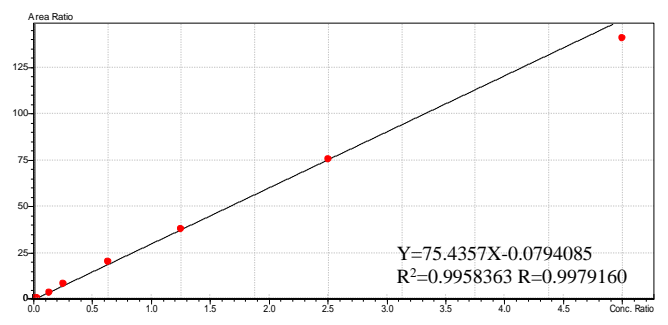

Figure 5. Representative calibration curves for PTU (a) and PTU-GLU (b). 


\subsubsection{Carry-Over}

Absence of carry-over was confirmed as no signal interference was observed in blank samples following the highest calibrator (data not shown).

\subsubsection{Accuracy and Precision}

The results of intra- and inter-day accuracy and precision are listed in Table 2. The experimental data fulfilled the guidelines' requirements as the mean accuracies (\%Bias) were all within $85-115 \%$ with \%RSD values not more than $15 \%[26,27]$.

Table 2. Percentage bias and relative standard deviation results of intra- and inter-day assay for PTU and PTU-GLU.

\begin{tabular}{|c|c|c|c|c|c|c|c|c|c|}
\hline & & \multicolumn{4}{|c|}{ PTU } & \multicolumn{4}{|c|}{ PTU-GLU } \\
\hline & & $0.1 \mu \mathrm{M}$ & $0.5 \mu \mathrm{M}$ & $5 \mu \mathrm{M}$ & $25 \mu \mathrm{M}$ & $0.1 \mu \mathrm{M}$ & $0.5 \mu \mathrm{M}$ & $5 \mu \mathrm{M}$ & $25 \mu \mathrm{M}$ \\
\hline \multirow{3}{*}{$\begin{array}{l}\text { Intra-Day Assay } \\
\qquad\left(\begin{array}{l}n=6) \\
\text { (a) }\end{array}\right.\end{array}$} & Measured ${ }^{a}$ & $0.107 \pm 0.0054$ & $0.574 \pm 0.038$ & $5.60 \pm 0.62$ & $24.9 \pm 0.5$ & $0.0907 \pm 0.0085$ & $0.575 \pm 0.018$ & $5.50 \pm 0.30$ & $26.3 \pm 0.9$ \\
\hline & \%Bias & $7.58 \%$ & $14.8 \%$ & $11.3 \%$ & $-0.485 \%$ & $-9.33 \%$ & & $\begin{array}{l}0.00 \% \\
10.0 \%\end{array}$ & $5.05 \%$ \\
\hline & $\%$ RSD & $5.02 \%$ & $6.61 \%$ & $9.42 \%$ & $9.87 \%$ & $9.38 \%$ & $\begin{array}{l}11.9 .9 \% \\
7.33 \%\end{array}$ & $\begin{array}{l}5.0 .0 \% \\
5.42 \%\end{array}$ & $\begin{array}{l}3.0 .3 \% \\
3.35 \%\end{array}$ \\
\hline \multirow{3}{*}{$\begin{array}{l}\text { Inter-Day Assay } \\
\quad(n=6)\end{array}$} & Measured ${ }^{\mathrm{a}}$ & $0.106 \pm 0.0079$ & $0.526 \pm 0.51$ & $5.40 \pm 0.73$ & $24.9 \pm 2.5$ & $0.0890 \pm 0.0085$ & $0.547 \pm 0.040$ & $5.74 \pm 0.35$ & $28.0 \pm 1.0$ \\
\hline & \%Bias & $6.35 \%$ & $5.21 \%$ & $\begin{array}{l}.402 \% \\
8.02 \%\end{array}$ & $-0.225 \%$ & $-11.0 \%$ & $\begin{array}{l}9.47 \% \\
9.040\end{array}$ & $\begin{array}{l}1.71 .7 \% \\
14.03\end{array}$ & $11.9 \%$ \\
\hline & $\%$ RSD & $\begin{array}{l}7.44 \% \\
7.40\end{array}$ & $5.46 \%$ & $\begin{array}{l}11.2 \% \\
\end{array}$ & $2.12 \%$ & $6.26 \%$ & $3.19 \%$ & $6.12 \%$ & $3.65 \%$ \\
\hline
\end{tabular}

${ }^{a}$ Measured mean concentration $(\mu \mathrm{M}, n=6) \pm \mathrm{SD}$.

\subsubsection{Recovery and Matrix Effect}

The recovery results for PTU and PTU-GLU, ranging from $98.2 \%$ to $114 \%$ with SD values within $15 \%$ are listed in Table 3 . The matrix effects for both analytes were also found to be insignificant.

Table 3. Recovery and matrix effect of PTU and PTU-GLU from human liver microsomes.

\begin{tabular}{|c|c|c|c|c|c|c|c|}
\hline & & \multicolumn{3}{|c|}{ PTU } & \multicolumn{3}{|c|}{ PTU-GLU } \\
\hline & & $0.5 \mu \mathrm{M}$ & $5 \mu \mathrm{M}$ & $25 \mu \mathrm{M}$ & $0.5 \mu \mathrm{M}$ & $5 \mu \mathrm{M}$ & $25 \mu \mathrm{M}$ \\
\hline $\begin{array}{l}\text { Recovery } \\
\quad(n=6)\end{array}$ & $\begin{array}{c}\text { Measured }^{\mathrm{a}} \\
\% \text { RSD }\end{array}$ & $\begin{array}{c}101.7 \% \pm 4.2 \% \\
4.1 \%\end{array}$ & $\begin{array}{c}115.1 \% \pm 14.0 \% \\
12.2 \%\end{array}$ & $\begin{array}{c}114.2 \% \pm 1.7 \% \\
1.5 \%\end{array}$ & $\begin{array}{c}114.6 \% \pm 12.1 \% \\
10.6 \%\end{array}$ & $\begin{array}{c}98.2 \% \pm 8.6 \% \\
8.8 \%\end{array}$ & $\begin{array}{c}106.1 \% \pm 0.6 \% \\
0.6 \%\end{array}$ \\
\hline Matrix Effect $(n=6)$ & $\begin{array}{c}\text { Measured } \\
\% \text { RSD }\end{array}$ & $\begin{array}{c}100 \% \pm 9.7 \% \\
9.7 \%\end{array}$ & $\begin{array}{c}86.0 \% \pm 11.8 \% \\
12.9 \%\end{array}$ & $\begin{array}{c}100 \% \pm 12.2 \% \\
12.2 \%\end{array}$ & $\begin{array}{c}99.3 \pm 8.6 \% \\
8.7 \%\end{array}$ & $\begin{array}{c}109 \% \pm 6.9 \% \\
6.3 \%\end{array}$ & $\begin{array}{c}87.6 \% \pm 4.1 \% \\
4.7 \%\end{array}$ \\
\hline
\end{tabular}

${ }^{a}$ Mean recovery calculated by Equation (2) $(n=3) \pm$ SD. ${ }^{\mathrm{b}}$ Mean matrix effect calculated by Equation (1) $(n=3) \pm \mathrm{SD}$

\subsubsection{Stability}

The stability of the samples was evaluated by using six replicates of quality control samples at three concentration levels under different storage conditions, including benchtop, auto-sampler, long-term and freeze-thaw stability. The data are listed in Table 4. Again, the stability profiles fulfilled the guidelines' requirement [26,27].

Table 4. Stability results for PTU and PTU-GLU at different storage conditions.

\begin{tabular}{|c|c|c|c|c|c|c|c|}
\hline \multirow{2}{*}{\multicolumn{2}{|c|}{ Storage Conditions }} & \multicolumn{3}{|c|}{ PTU } & \multicolumn{3}{|c|}{ PTU-GLU } \\
\hline & & $0.5 \mu \mathrm{M}$ & $5 \mu \mathrm{M}$ & $25 \mu \mathrm{M}$ & $0.5 \mu \mathrm{M}$ & $5 \mu \mathrm{M}$ & $25 \mu \mathrm{M}$ \\
\hline $\begin{array}{l}\text { Benchtop } \\
(n=6) \\
20^{\circ} \mathrm{C}, 6 \mathrm{~h}\end{array}$ & $\begin{array}{c}\text { Measured } \\
\text { \%Bias } \\
\% \text { RSD }\end{array}$ & $\begin{array}{c}0.428 \pm 0.011 \\
-14.5 \% \\
2.58 \%\end{array}$ & $\begin{array}{l}5.13 \pm 0.15 \\
2.69 \% \\
2.83 \%\end{array}$ & $\begin{array}{c}24.9 \pm 2.7 \\
0.473 \% \\
11.0 \%\end{array}$ & $\begin{array}{c}0.558 \pm 0.035 \\
11.8 \% \\
6.22 \%\end{array}$ & $\begin{array}{c}5.63 \pm 0.54 \\
12.6 \% \\
9.62 \%\end{array}$ & $\begin{array}{c}25.47 \pm 1.2 \\
1.87 \% \\
2.34 \%\end{array}$ \\
\hline $\begin{array}{c}\text { Auto-Sampler } \\
(n=6) \\
4{ }^{\circ} \mathrm{C}, 72 \mathrm{~h}\end{array}$ & $\begin{array}{c}\text { Measured } \\
\text { \%Bias } \\
\% \text { RSD }\end{array}$ & $\begin{array}{c}0.496 \pm 0.030 \\
-7.67 \% \\
5.97 \%\end{array}$ & $\begin{array}{c}5.54 \pm 0.16 \\
10.8 \% \\
2.91 \%\end{array}$ & $\begin{array}{c}24.8 \pm 1.0 \\
0.885 \% \\
0.416 \%\end{array}$ & $\begin{array}{c}0.49 \pm 0.039 \\
-12 \% \\
7.86 \%\end{array}$ & $\begin{array}{c}4.47 \pm 0.32 \\
-10.5 \% \\
7.36 \%\end{array}$ & $\begin{array}{c}23.5 \pm 0.9 \\
-6.06 \% \\
3.91 \%\end{array}$ \\
\hline $\begin{array}{l}\text { Long-Term } \\
\quad(n=6) \\
-80^{\circ} \mathrm{C}, 20 \mathrm{~d}\end{array}$ & $\begin{array}{c}\text { Measured } \\
\text { \%Bias } \\
\% \text { RSD }\end{array}$ & $\begin{array}{c}0.481 \pm 0.029 \\
-3.97 \% \\
6.06 \%\end{array}$ & $\begin{array}{c}4.95 \pm 0.46 \\
-0.893 \% \\
9.28 \%\end{array}$ & $\begin{array}{c}23.8 \pm 2.6 \\
-4.76 \% \\
10.9 \%\end{array}$ & $\begin{array}{c}0.429 \pm 0.45 \\
-14.4 \% \\
10.5 \%\end{array}$ & $\begin{array}{c}5.88 \pm 0.82 \\
7.53 \% \\
14.5 \%\end{array}$ & $\begin{array}{c}22.7 \pm 3.0 \\
-8.78 \% \\
13.2 \%\end{array}$ \\
\hline $\begin{array}{c}\text { Freeze-Thaw } \\
(n=6) \\
-80^{\circ} \mathrm{C}, \mathrm{Up} \text { to } 3 \text { Cycles }\end{array}$ & $\begin{array}{l}\text { Measured a } \\
\text { \%Bias } \\
\text { \%RSD }\end{array}$ & $\begin{array}{c}0.455 \pm 0.056 \\
-9.04 \% \\
12.3 \%\end{array}$ & $\begin{array}{c}5.41 \pm 0.68 \\
-8.19 \% \\
12.6 \%\end{array}$ & $\begin{array}{l}26.3 \pm 1.0 \\
5.09 \% \\
3.96 \%\end{array}$ & $\begin{array}{c}0.517 \pm 0.067 \\
3.43 \% \\
13.0 \%\end{array}$ & $\begin{array}{c}5.20 \pm 0.42 \\
4.01 \% \\
8.15 \%\end{array}$ & $\begin{array}{c}25.7 \pm 2.6 \\
2.66 \% \\
10.0 \%\end{array}$ \\
\hline
\end{tabular}

${ }^{\text {a }}$ Mean recovery calculated by Equation (2) $(n=3) \pm$ standard deviation (SD). 


\subsection{Application to In Vitro Metabolism Study}

The analytical methods for the quantification of PTU in biological matrices such as plasma, milk, urine and tissue samples have been reported [24,28-30]. However, to our knowledge, there is no established protocol suitable for the examination of glucuronidation of PTU. Therefore, in the present study, we developed and validated a reliable method for the simultaneous measurement of PTU and PTU-Glu and subsequently applied it to study the in vitro metabolism of PTU in HLMs.

\subsubsection{Formation of PTU-GLU}

The formation of PTU glucuronide by HLMs was analyzed by the HPLC-MS/MS system, with the representative result illustrated in Figure 6. No metabolite was observed in the negative control. The result was consistent with the research published in 1977, which confirmed glucuronide conjugation of PTU in guinea pig liver microsome [15]. As shown in Figure 7, no PTU-GLU formation was observed in the incubation mixture in the absence of recombinant human UGT1A9 isoform. Clearly, UGT1A9 plays an important role in the glucuronidation of PTU.

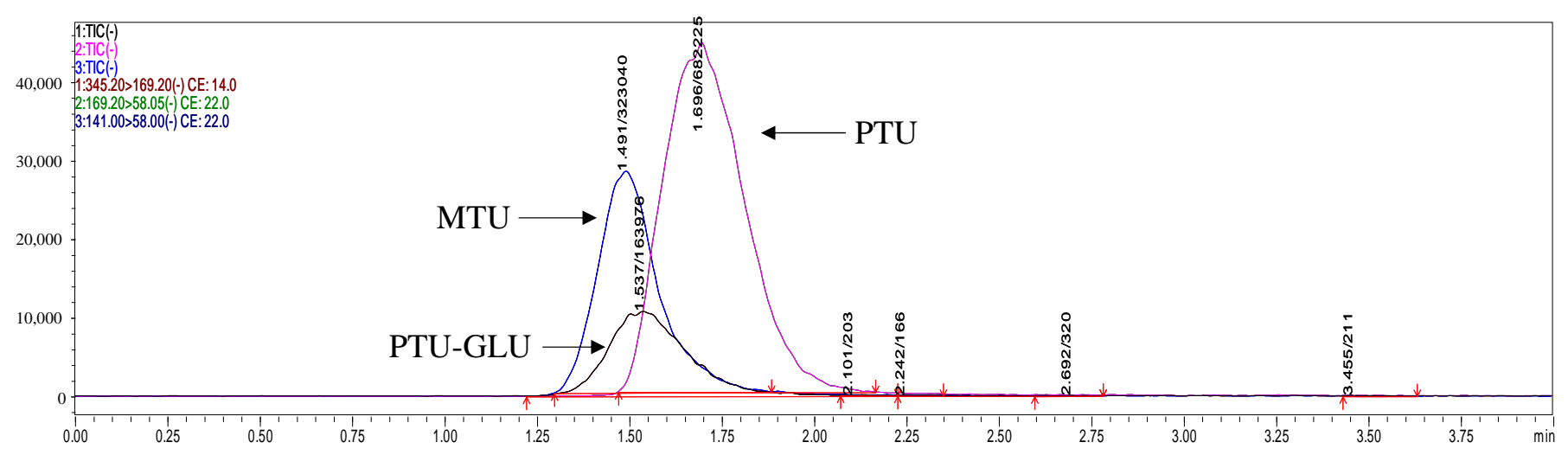

Figure 6. Representative HPLC profile of PTU and PTU-GLU. Propylthiouracil was incubated with the HLMs system at $37^{\circ} \mathrm{C}$ for $60 \mathrm{~min}$ as described in Materials and Methods (Section 3.4).

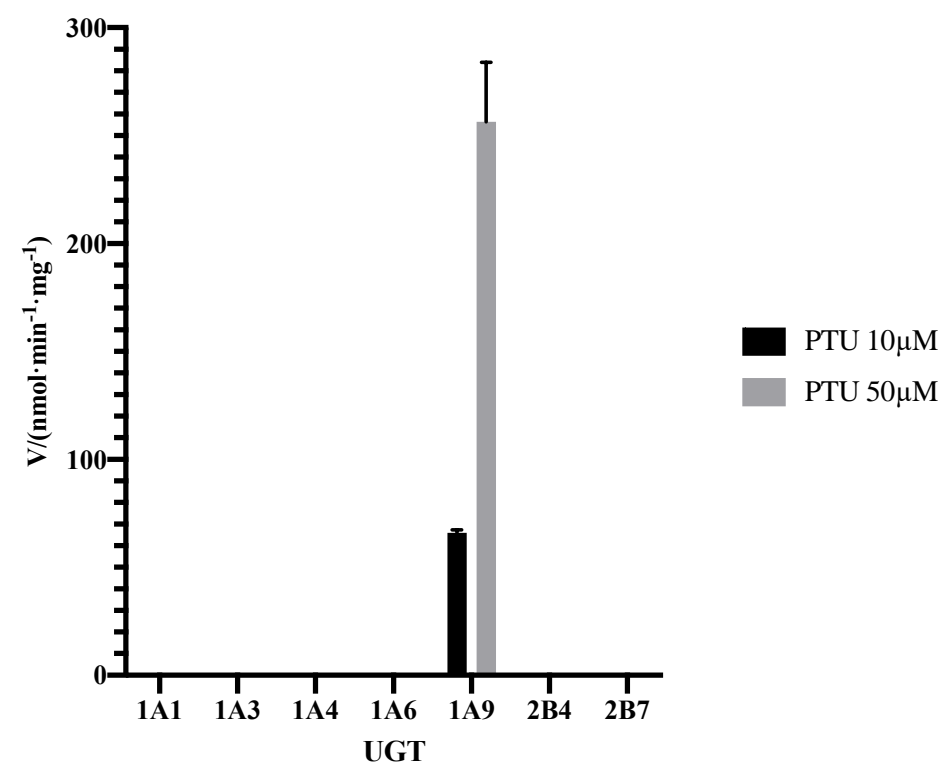

Figure 7. Formation rate of PTU-GLU by recombinant human UGTs. PTU was incubated with different UGTs at $37^{\circ} \mathrm{C}$ for $60 \mathrm{~min}$ as described in Materials and Methods (Section 3.4). Each point represents the average of three replicates. 


\subsubsection{Inhibitory Study}

As shown in Figure 8, addition of $10 \mu$ M UGT1A9 inhibitor (magnolol) exhibited significant suppression on PTU glucuronidation, confirming our finding reported in Figure 7. Magnolol inhibited PTU glucuronidation in a concentration-dependent manner in both HLMs and UGT1A9 (Figure 9). Interestingly, the IC $_{50}$ of magnolol for both HLMs and UGT1A9 were almost identical (Table 5), suggesting that UGT1A9 was the major UGT isoform in HLMs that mediates the glucuronidation of PTU. Of note, UGT2B4 inhibitor fluconazole showed a significant suppressive effect at a high concentration of $50 \mu \mathrm{M}$ while other UGT inhibitors also slightly slowdown the glucuronidation. Such phenomenon may be due to their weak inhibitory specificity to UGT1A9. However, it is still unclear whether UGT1A9 is the only isoform of UGTs responsible for PTU glucuronidation.

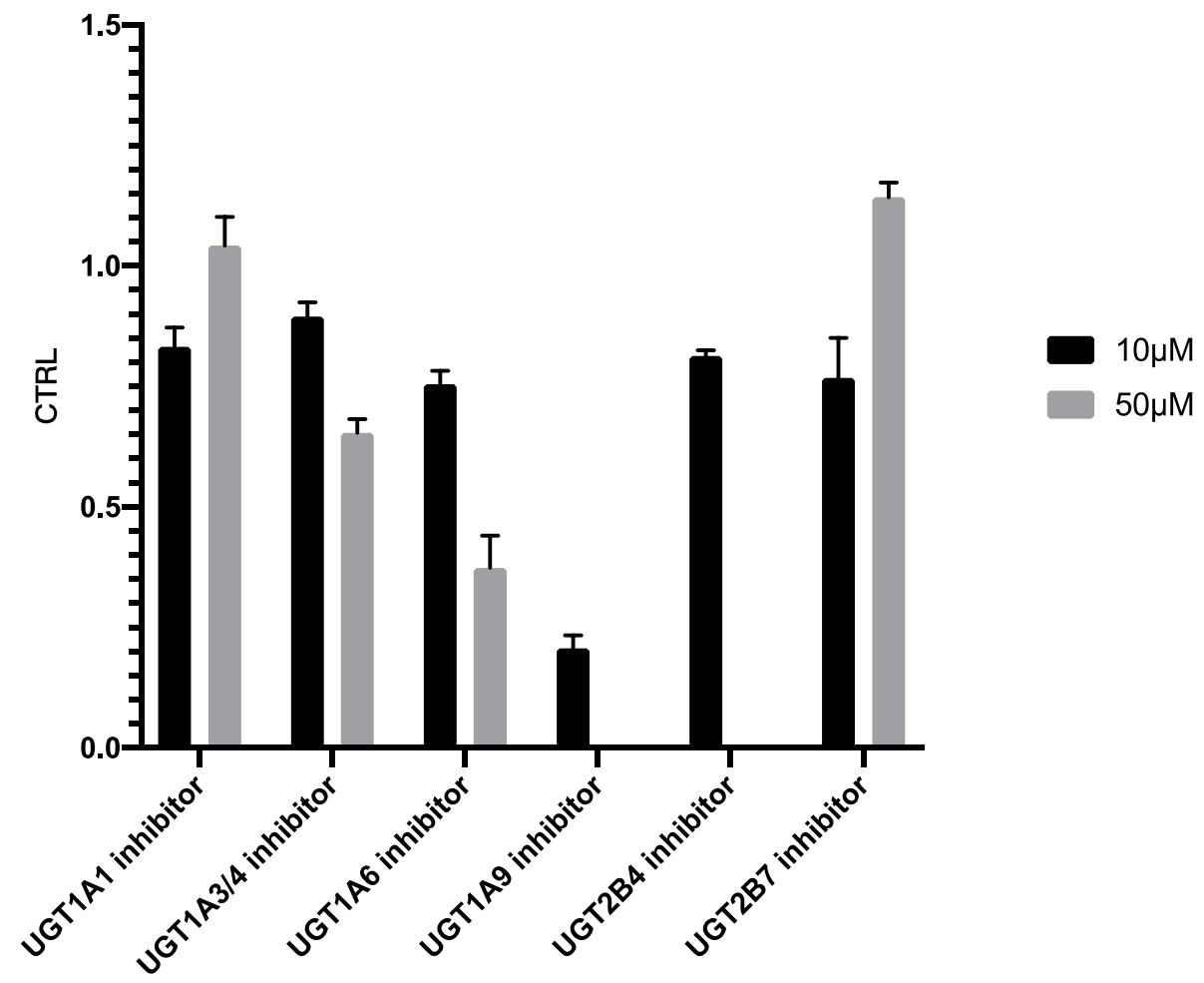

Figure 8. Inhibition of propylthiouracil glucuronidation in HLMs by different UGT inhibitors. Each point represents the average of three replicates.
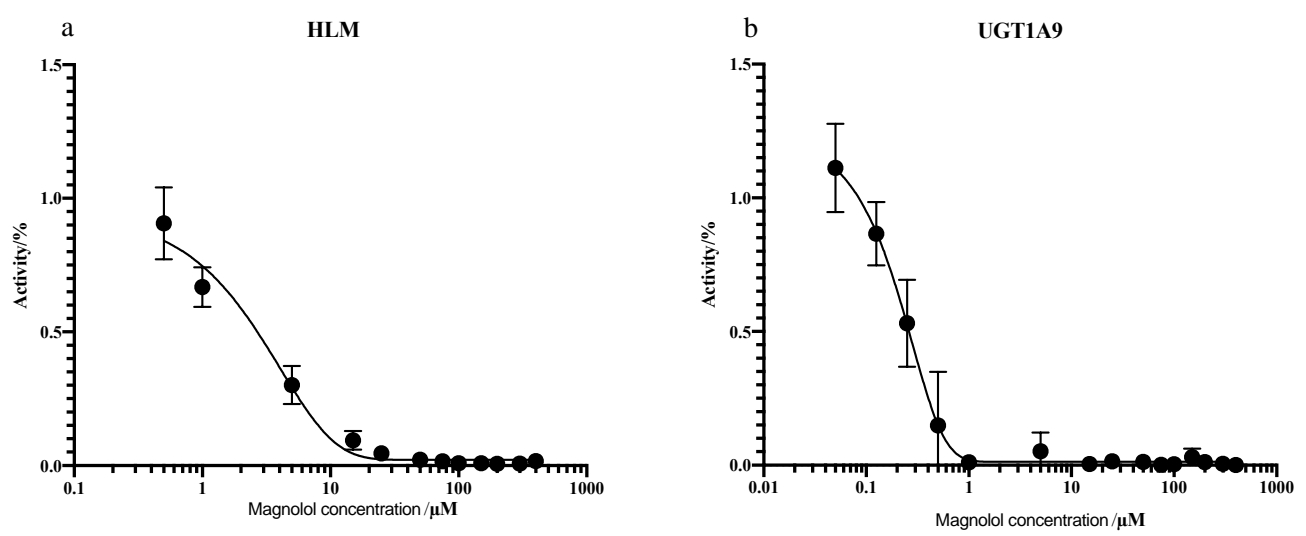

Figure 9. Inhibition of PTU glucuronidation in HLMs (a) and UGT1A9 (b) by magnolol. Each point represents the average of three replicates. 
Table 5. Inhibition of PTU glucuronidation in HLMs and recombinant UGT1A9 by magnolol.

\begin{tabular}{cc}
\hline & ${\text { Magnolol } \text { IC }_{50}(\mu \mathbf{M})}$ \\
\hline HLMs & 1.028 \\
UGT1A9 & 1.160 \\
\hline
\end{tabular}

\subsubsection{Enzymatic Kinetics Study}

The PTU-GLU formation in the UGT1A9 and HLMs was analyzed to estimate the kinetic parameters. As illustrated in Figure 10, the substrate concentration-glucuronidation velocity curves exhibited typical Michaelis-Menten kinetics for both incubation systems. The mean $K_{m}$ value was calculated to be $15.27 \mu \mathrm{M}$ for UGT1A9 and 22.76 $\mu \mathrm{M}$ for HLMs. For $V_{\text {max }}$, the values were $352.3 \mathrm{nmol} / \mathrm{min} / \mathrm{mg}$ and $220.0 \mathrm{nmol} / \mathrm{min} / \mathrm{mg}$, respectively (Table 6). Lower $K_{m}$ and higher $V_{\max }$ indicate a higher affinity and catalytic activity. The results showed that PTU had a good affinity to UGT1A9. Based on the result of these in vitro experiments, a physiologically-based pharmacokinetic model of PTU could be developed and validated by clinical data, enabling an accurate prediction on its hepatotoxicity and the risk of drug-drug interaction [31-34].

HLM

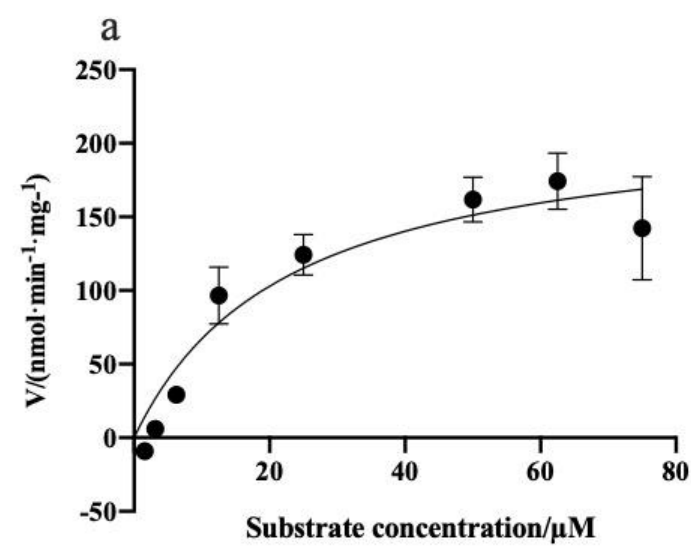

UGT1A9

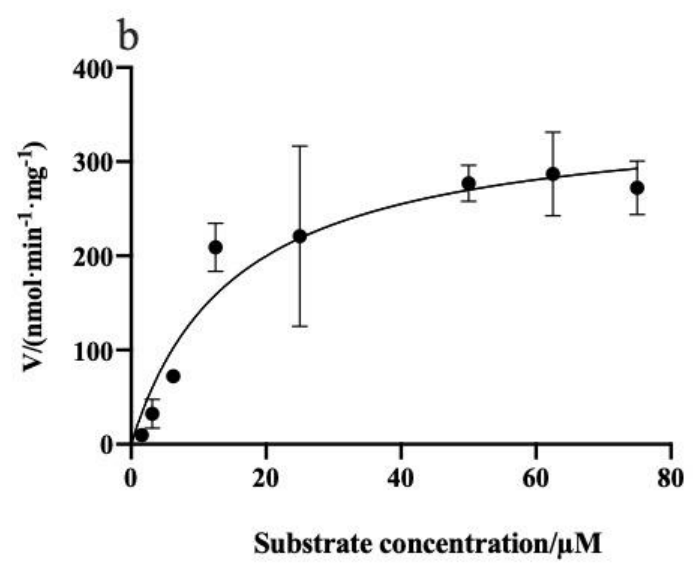

Figure 10. Kinetics of PTU glucuronidation by HLMs (a) and UGT1A9 (b). Each point represents the average of three replicates.

Table 6. Kinetic parameters of propylthiouracil glucuronidation in HLMs and recombinant human UGT1A9.

\begin{tabular}{cccc}
\hline Enzyme & $\boldsymbol{K}_{\boldsymbol{m}}(\boldsymbol{\mu M})^{\mathbf{a}}$ & $\boldsymbol{V}_{\max }(\mathbf{n m o l} / \mathbf{m i n} / \mathbf{m g})^{\mathbf{a}}$ & $\begin{array}{c}\text { Clearance } \\
(\mathbf{m L} / \mathbf{m i n} / \mathbf{m g})^{\mathbf{b}}\end{array}$ \\
\hline HLMs & $22.76 \pm 12.29$ & $220.0 \pm 43.35$ & 9.67 \\
UGT1A9 & $15.27 \pm 7.73$ & $352.3 \pm 56.38$ & 23.07 \\
\hline
\end{tabular}

${ }^{\mathrm{a}} K_{m}$ and $V_{\max }$ were presented as mean value $\pm \mathrm{SD}(n=6) .{ }^{\mathrm{b}}$ The clearance values were estimated by $V_{\max } / K_{m}$.

\section{Materials and Methods}

\subsection{Chemicals and Reagents}

Propylthiouracil (PTU, purity > 98\%) was obtained from Aladdin Biochemical Technology Co., Ltd. (Shanghai, China). Propylthiouracil N-B-D-glucuronide (PTU-GLU, purity $>98 \%$ ) was provided by Shanghai ZZBIO Biochemical Technology Co., Ltd. (Shanghai, China). Methylthiouracil (MTU, internal standard, purity >98\%), hesperetin (purity > 98\%), nilotinib (purity $>98 \%$ ), magnolol (purity $>98 \%$ ), silybin (purity $>98 \%$ ), fluconazole (purity $>98 \%$ ) and mefenamic acid (purity $>98 \%$ ) were all purchased from Shanghai Yuanye Bio-Technology Co., Ltd. (Shanghai, China). Hecogenin (purity $>98 \%$ ) was supplied from Chengdu Pufei De Biotech Co., Ltd. (Chengdu, China); uridine 5'-diphosphoglucuronic acid (UDPGA, purity > 98\%) and alamethicin (purity > 98\%) were obtained from Sigma- 
Aldrich Co., Ltd. (Merck, Shanghai, China). Pooled human liver microsomes (HLMs) and human recombinant UGT1A1 and 1A6 were purchased from Corning Incorporated (Corning, NY, USA). Other recombinant human UGT isoforms (1A3, 1A4, 1A9, 2B4 and 2B7) were obtained from Research Institute for Liver Diseases Co. Ltd. (Shanghai, China). Magnesium chloride $\left(\mathrm{MgCl}_{2}\right.$, purity $>98 \%$ ) and tris-(hydroxymethyl) aminomethane (Tris, purity $>98 \%$ ) were purchased from Sinopharm Chemical Reagent Co., Ltd. (Shanghai, China). A Milli-Q-plus system (Millipore, Bedford, MA, USA) was utilized to generate ultrapure water. Other reagents were purchased from standard chemical suppliers and were of analytical grade or higher.

\subsection{Instrumental Conditions of HPLC-MS/MS}

Determination of the analytes was conducted with the HPLC-MS/MS-8060 system (Shimadzu Scientific Instruments, Columbia, MD, USA). The mobile phase A consisted of $0.1 \%$ of formic acid in water and phase B consisted of $0.1 \%$ formic acid in methanol and acetonitrile $(2: 1, v / v)$. Chromatographic separation was achieved on a ZORBAX ExtendC18 column $(2.1 \times 50 \mathrm{~mm}, 1.8 \mu \mathrm{m}$; Agilent Technologies, Waldbronn, Germany) through isocratic delivery of the mobile phase $(\mathrm{A}: \mathrm{B}=40: 60)$ at $0.1 \mathrm{~L} / \mathrm{min}$ at $35^{\circ}$. The injection volume was $1 \mu \mathrm{L}$. Along with multiple reaction monitoring (MRM) mode, electrospray ionization was performed at its negative ion mode using nitrogen as the nebulizing, drying, and heating gas with the flow rate values set at $3.0,10.0$, and $10.0 \mathrm{~mL} / \mathrm{min}$, respectively.

The heat block temperature was set at $400^{\circ} \mathrm{C}$ with the desolvation line (DL) temperature at $250{ }^{\circ} \mathrm{C}$ and interface temperature at $300{ }^{\circ} \mathrm{C}$. Other operating parameters were set as follows: conversion voltage, $10 \mathrm{kV}$; detector voltage, $2.08 \mathrm{kV}$; collision induced dissociation (CID) gas, $270 \mathrm{kPa}$; interface voltage, $4.0 \mathrm{kV}$; nebulizer gas, $2.0 \mathrm{~L} / \mathrm{min}$; heating gas, $10 \mathrm{~L} / \mathrm{min}$; and drying gas, $10 \mathrm{~L} / \mathrm{min}$.

\subsection{Calibration Standards and Quality Control (QC) Samples}

PTU primary stock solution was prepared by dissolving $8.5 \mathrm{mg}$ of PTU in $5 \mathrm{~mL}$ of methanol: water $(1: 1, v / v)$ to obtain a final concentration of $1.70 \mathrm{mg} / \mathrm{mL}(10 \mathrm{mM})$. To make a stock solution of $1 \mathrm{mg} / \mathrm{mL}$ PTU-GLU $(2.86 \mathrm{mM}), 1 \mathrm{mg}$ of PTU-GLU was dissolved into an appropriate amount of methanol. For IS, the stock solution of MTU $(1 \mathrm{mM})$ was prepared by dissolving $3.6 \mathrm{mg}$ of MTU in $25 \mathrm{~mL}$ of methanol: acetonitrile $(2: 1, v / v)$. All stock solutions were transferred to Eppendorf vials and stored at $-20^{\circ} \mathrm{C}$ before usage.

The calibration standards and quality control samples were prepared by proper dilution of the stock solutions with Tris- $\mathrm{HCl}$ solution and mixed with inactivated HLMs, alamethicin, and $\mathrm{MgCl}_{2}$. The concentrations of calibration standards ranged from $0.1 \mu \mathrm{M}$ to $50 \mu \mathrm{M}(0.1,0.5,1,5,10,25$ and $50 \mu \mathrm{M})$ for PTU and PTU-GLU. At the same time, QC concentrations were set at $0.1 \mu \mathrm{M}$ (LLOQ), $0.5 \mu \mathrm{M}$ (quality control at low concentration), $5 \mu \mathrm{M}$ (quality control at middle concentration), and $25 \mu \mathrm{M}$ (quality control at high concentration). The final IS concentration was $10 \mu \mathrm{M}$. Samples used for calibration and QC were freshly prepared at the beginning of the experimental day.

\subsection{Biological Sample Preparation}

The in vitro metabolic study was carried out using a protocol modified from a previous report [35]. To formulate the incubation system, a $10 \mu \mathrm{L}$ mixture of alamethicin $(250 \mu \mathrm{g} / \mathrm{mL})$ and $\mathrm{MgCl}_{2}(50 \mathrm{mM})$, precalculated amounts of PTU $(200 \mu \mathrm{M})$ and Tris- $\mathrm{HCl}(50 \mathrm{mM}$, $\mathrm{pH}=7.4$ ) were mixed vigorously and kept on ice for $15 \mathrm{~min}$. Upon addition of $5 \mu \mathrm{L}$ of HLMs $(5 \mathrm{mg} / \mathrm{mL})$ or recombinant human UGTs $(2 \mathrm{mg} / \mathrm{mL})$, preincubation was applied at $37^{\circ} \mathrm{C}$ for $10 \mathrm{~min}$, followed by the addition of $10 \mu \mathrm{L}$ of UDPGA $(25 \mathrm{mM})$ to start the reaction. Then, 60 min later, a double volume of ice-cold MTU acetonitrile solution $(10 \mu \mathrm{M})$ was added into the system along with thorough vortexing for termination. Centrifugation at $18,000 \mathrm{~g}$ was then performed at $4{ }^{\circ} \mathrm{C}$ for 15 min to obtain supernatant for HPLC-MS/MS analysis. 


\subsection{Assay Validation}

This bioanalytical method was validated in accordance with the guidelines from the FDA and International Conference on Harmonization of Technical Requirements for Registration of Pharmaceuticals for Human Use (ICH) guidelines [26,27].

The confirmation of selectivity was achieved by evaluating the possible interference from the biological matrix and inhibitor. The acceptance criteria are defined as no co-eluting peaks greater than $20 \%$ of the PTU/PTU-GLU at the LLOQ level and $5 \%$ for IS.

The sensitivity is represented by LLOQ and it is identified as the guidelines specified $[26,27]$.

Nine calibration standards, including seven non-zero and two blank groups (one with IS and the other without), were used to construct the calibration curves by plotting the peak area ratios (analyte/IS) vs. concentrations of the analytes. Linear regression $(y=m x+c)$ and weighted $\left(1 / \mathrm{x}^{2}\right)$ values were utilized to produce the calibration curve with correlation coefficients $\left(\mathrm{R}^{2}\right)$ greater than 0.99 .

The carry-over was assessed by analyzing two blank samples following the most concentrated calibrator. With the peak area less than 20\% of LLOQ and 5\% of IS, the carry-over effect could be considered negligible.

Inter-day accuracy and precision were determined by analyzing samples at each quality control concentration daily for three successive days, while intra-day values were evaluated by the analysis of the quality control samples on the same day. All analyses were performed in six replicates. Bias in terms of percentage was utilized and expected to be within $\pm 15 \%$ (except for $\pm 20 \%$ at LLOQ) for good accuracy. Precision was defined as the $\%$ RSD with the same acceptance criteria.

To assess the matrix effect, blank HLMs were spiked with IS, PTU, and PTU-GLU at low, middle and high quality control concentrations. Neat solutions for both analytes were also prepared with methanol at the same concentration levels. The IS normalized matrix factor was used to determine the matrix effect using Equation (1) shown below.

\section{IS Normalized Matrix Effect}

$$
=\frac{\text { Mean peak area ratio of analyte /IS in matrix }}{\text { Mean peak area ratio of analyte/IS in solvent }} \times 100 \%
$$

Analytes at low, middle and high quality control concentrations and IS were incubated in HLMs as described above (Section 3.4), followed by centrifugation. Supernatant was obtained for chromatographic analysis (Signal I). Similarly, analytes free supernatant was first recovered from the HLMs and then mixed with analytes and IS at the same level (Signal II). The recovery was determined by comparing the peak areas using the following Equation (2).

$$
\text { Recovery }(\%)=\frac{\text { Analyte Signal I }}{\text { Analyte Signal II }} \times 100 \%
$$

Similar calculations can be found in a previous report [36].

Benchtop (short-term) stability was conducted under the common laboratory conditions $\left(20^{\circ} \mathrm{C}\right)$ for $6 \mathrm{~h}$ (the same duration of the experiments). The stability of analytes in the matrix stored in the $-80^{\circ} \mathrm{C}$ freezer was analyzed to evaluate long-term variation. To assess the impact of repeatedly removing samples from the freezer, the freeze-thaw stability of the analytes was performed after three freeze-thaw cycles. Similarly, auto-sampler stability was also carried out. A mean percentage of analyte remaining ranging from $85 \%$ to $115 \%$ indicates sample stability.

\subsection{In Vitro Metabolism Study}

\subsubsection{Assays of PTU-GLU Determination}

The formation of PTU-GLU was attempted in reaction systems containing recombinant human UGT1A1, 1A3, 1A4, 1A6, 1A9, 2B4, 2B7 or pooled HLMs, using the incubation method described above for the in vitro study and HPLC-MS/MS analysis. 


\subsubsection{Enzymatic Inhibition Study}

Several small-molecule chemicals have demonstrated potent and selective inhibitory effects towards different UGT isoforms, which could be utilized for further screening. In the initial study, HLMs incubation systems were mixed with nilotinib (UGT1A1 inhibitor) [37], hecogenin (UGT1A3/1A4 inhibitor) [38], silybin (UGT1A6 inhibitor) [39], magnolol (UGT1A9 inhibitor) [30], fluconazole (UGT2B4 inhibitor) [40] or mefenamic acid (UGT2B7 inhibitor) [41] at two different concentrations, namely $10 \mu \mathrm{M}$ and $50 \mu \mathrm{M}$. Based on the results from the initial study, magnolol was further tested for its inhibitory effect on PTU glucuronidation in HLMs and UGT1A9. Various concentrations of magnolol $(0.1-400 \mu \mathrm{M})$ were added to the incubation system to determine the half-inhibition concentrations $\left(\mathrm{IC}_{50}\right)$ as described in Section 3.4.

\subsubsection{Kinetic Study}

To evaluate the kinetic parameters for glucuronidation, PTU at various concentrations (1-75 $\mu \mathrm{M})$ was incubated with HLMs or recombinant human UGT1A9 separately.

Enzymatic kinetics of metabolism follows a simple Michaelis-Menten equation that describes the relationship between substrate concentration and reaction velocity (Equation (3)).

$$
V=\frac{V_{\max } \times[S]}{K_{m}+[S]}
$$

where $V$ is defined as the initial velocity of the metabolic reaction and $V_{\max }$ is the maximum rate. [S] stands for the concentration of substrate and $K_{m}$ is the Michaelis constant defined as the substrate concentration at half of the $V_{\max }$.

\section{Conclusions}

The HPLC-MS/MS method for the simultaneous quantification of PTU and its metabolite (PTU-GLU) was successfully developed and validated. This reliable bioanalytical protocol was subsequently applied to examine the in vitro metabolism of PTU. Glucuronidation of PTU was confirmed in pooled human HLMs while UGT1A9 was identified as an important UGT isoform responsible for the glucuronidation of PTU. The information obtained from this study will facilitate future mechanistic investigation on the hepatoxicity of PTU and may optimize its clinical application. Further investigation on this topic is warranted.

Author Contributions: Conceptualization, X.X.; methodology, M.L. and Q.H.; software, M.L. and Q.H.; validation, L.Y.; formal analysis, Z.T.; writing-original draft preparation, M.L., Q.H., H.-S.L. and X.X.; writing - review and editing, M.L. and Q.H.; supervision, X.W.; project administration, X.Z.; funding acquisition, H.-S.L. and X.X. All authors have read and agreed to the published version of the manuscript.

Funding: This research was jointly funded by Shanghai Municipal Commission of Health and Family Planning (No. 201840057) and a framework of China-Korea international cooperation program managed by National Natural Science Foundation of China and National Research Foundation of Korea (No. 82011540409). The APC was funded by H.-S.L. with his personal resource.

Institutional Review Board Statement: Not applicable.

Informed Consent Statement: Not applicable.

Data Availability Statement: Data are contained within the article.

Conflicts of Interest: The authors declare no conflict of interest.

\section{Abbreviations}

ESI, electrospray ionization; HLMs, human liver microsomes; IS, internal standard; LLOQ, lower limit of quantiifcation; MRM, multiple reaction monitoring; MS, mass spectrometry; MTU, methylthiouracil; PTU, propylthiouracil; PTU-GLU, propylthiouracil glucuronide; UGTs, uridine $5^{\prime}$-diphospho-glucuronosyltransferases. 


\section{References}

1. Douglas, S.R.; Burch, H.B.; Cooper, D.S.; Greenlee, M.C.; Laurberg, P.; Maia, A.L.; Rivkees, S.A.; Samuels, M.; Sosa, J.A.; Stan, M.N.; et al. American thyroid association guidelines for diagnosis and management of hyperthyroidism and other causes of thyrotoxicosis. Thyroid 2016, 26, 1343-1421. [CrossRef]

2. Geffner, D.L.; Azukizawa, M.; Hershman, J.M. Propylthiouracil blocks extrathyroidal conversion of thyroxine to triiodothyronine and augments thyrotropin secretion in man. J. Clin. Investig. 1975, 55, 224-229. [CrossRef]

3. Li, X.; Jin, S.; Fan, Y.; Fan, X.; Tang, Z.; Cai, W.; Yang, J.; Xiang, X. Association of HLA-C*03:02 with methimazole-induced liver injury in Graves' disease patients. Biomed. Pharmacother. 2019, 117, 109095. [CrossRef]

4. Jin, S.; Li, X.; Fan, Y.; Fan, X.; Dai, Y.; Lin, H.; Cai, W.; Yang, J.; Xiang, X. Association between genetic polymorphisms of SLCO1B1 and susceptibility to methimazole-induced liver injury. Basic Clin. Pharmacol. Toxicol. 2019, 125, 508-517. [CrossRef] [PubMed]

5. Azizi, F.; Amouzegar, A. Management of hyperthyroidism during pregnancy and lactation. Eur. J. Endocrinol. 2011, 164, 871-876. [CrossRef] [PubMed]

6. Chalasani, N.P.; Maddur, H.; Russo, M.W.; Wong, R.J.; Reddy, K.R. ACG clinical guideline: Diagnosis and management of idiosyncratic drug-induced liver injury. Am. J. Gastroenterol. 2021, 116, 878-898. [CrossRef] [PubMed]

7. Rivkees, S.A. 63 years and 715 days to the "boxed warning": Unmasking of the propylthiouracil problem. Int. J. Pediatr. Endocrinol. 2010, 2010, 1-3. [CrossRef]

8. Koch, L. Therapy: Propylthiouracil use associated with severe hepatotoxicity in children. Nat. Rev. Endocrinol. 2010, 6, 416. [CrossRef] [PubMed]

9. Amisha, F.; Rehman, A. Propylthiouracil (PTU); StatPearls: Treasure Island, FL, USA, 2021.

10. DAVA. Propylthiouracil [Package Insert]. 2015. Available online: https://www.accessdata.fda.gov/drugsatfda_docs/label/2016 /006188s006025lbl.pdf (accessed on 17 November 2021).

11. Hadjiangelis, N.P.; Harkin, T.J. Propylthiouracil-related diffuse alveolar hemorrhage with negative serologies and without capillaritis. Respir. Med. 2007, 101, 865-867. [CrossRef]

12. Lee, E.; Miki, Y.; Hosokawa, M.; Sayo, H.; Kariya, K. Oxidative metabolism of propylthiouracil by peroxidases from rat bone marrow. Xenobiotica 1988, 18, 1135-1142. [CrossRef]

13. Kimio, K.; Tadashi, S.; Shiroh, O.; Eibai, L. Inhibition of hepatic glutathione transferases by propylthiouracil and its metabolites. Biochem. Pharmacol. 1986, 35, 1475-1479. [CrossRef]

14. Lindsay, R.H.; Aboul-Enein, H.Y.; Morel, D.; Bowen, S. Synthesis and antiperoxidase activity of propylthiouracil derivatives and metabolites. J. Pharm. Sci. 1974, 63, 1383-1386. [CrossRef] [PubMed]

15. Lindsay, R.H.; Cash, A.G.; Vaughn, A.W.; Hill, J.B. Glucuronide conjugation of 6-n-propyl-2-thiouracil and other antithyroid drugs by guinea pig liver microsomes in vitro. Biochem. Pharmacol. 1977, 26, 617-623. [CrossRef]

16. Court, M.H.; Zhang, X.; Ding, X.; Yee, K.K.; Hesse, L.M.; Finel, M. Quantitative distribution of mRNAs encoding the 19 human UDP-glucuronosyltransferase enzymes in 26 adult and 3 fetal tissues. Xenobiotica 2012, 42, 266-277. [CrossRef]

17. Van Den Anker, J.; Reed, M.D.; Allegaert, K.; Kearns, G.L. Developmental changes in pharmacokinetics and pharmacodynamics. J. Clin. Pharmacol. 2018, 58, S10-S25. [CrossRef] [PubMed]

18. Strassburg, C.P. Developmental aspects of human hepatic drug glucuronidation in young children and adults. Gut 2002, 50, 259-265. [CrossRef] [PubMed]

19. Rivkees, S.A.; Mattison, D.R. Propylthiouracil (PTU) hepatoxicity in children and recommendations for discontinuation of use. Int. J. Pediatr. Endocrinol. 2009, 2009, 1-8. [CrossRef]

20. Karras, S.; Memi, E.; Kintiraki, E.; Krassas, G.E. Pathogenesis of propylthiouracil-related hepatotoxicity in children: Present concepts. J. Pediatr. Endocrinol. Metab. 2012, 25, 623-630. [CrossRef]

21. De Wildt, S.N.; Kearns, G.L.; Leeder, J.S.; Van Den Anker, J.N. Glucuronidation in humans. Clin. Pharmacokinet. 1999, 36, 439-452. [CrossRef]

22. Anderson, G.D. Children versus adults: Pharmacokinetic and adverse-effect differences. Epilepsia 2002, 43, 53-59. [CrossRef]

23. Abdul-Fattah, A.M.; Bhargava, H.N. Development and validation of a high-performance liquid chromatographic method for the analysis of propylthiouracil in pharmaceuticals. Drug Dev. Ind. Pharm. 2001, 27, 831-835. [CrossRef]

24. Mendes, G.D.; Bittencourt, S.; Vespasiano, C.F.P.; Babadópulos, T.; Gagliano-Jucá, T.; Arruda, A.M.M.; Perissutti, E.; Frecentese, F.; De Nucci, G. Propylthiouracil quantification in human plasma by high-performance liquid chromatography coupled with electrospray tandem mass spectrometry: Application in a bioequivalence study. J. Chromatogr. B 2014, 969, 19-28. [CrossRef]

25. Zakrzewski, R. Determination of propylthiouracil in pharmaceutical formulation by high-performance liquid-chromatography with a post-column iodine-azide reaction as a detection system. Arch. Pharm. Res. 2008, 31, 1622-1630. [CrossRef]

26. ICH. ICH Harmonised Guideline M10-Bioanalytical Method Validation. 2018. Available online: https://www.fda.gov/media/12 8343/ download (accessed on 17 November 2021).

27. FDA. Guidance for Industry-Bioanalytical Method Validation. 2018. Available online: https://www.fda.gov/media/70858/ download (accessed on 17 November 2021).

28. Cirkva, A.; Stastny, K. Method for the determination of thyreostats in milk samples using LC-MS/MS. Food Addit. Contam. Part. A Chem. Anal. Control. Expo. Risk Assess. 2013, 30, 983-986. [CrossRef] 
29. Asea, P.E.; MacNeil, J.D.; Boison, J.O. An analytical method to screen for six thyreostatic drug residues in the thyroid gland and muscle tissues of food producing animals by liquid chromatography with ultraviolet absorption detection and liquid chromatography/mass spectrometry. J. AOAC Int. 2006, 89, 567-575. [CrossRef] [PubMed]

30. Lohmus, M.; Kallaste, K.; Le Bizec, B. Determination of thyreostats in urine and thyroid gland by ultra high performance liquid chromatography tandem mass spectrometry. J. Chromatogr. A 2009, 1216, 8080-8089. [CrossRef] [PubMed]

31. Docci, L.; Umehara, K.; Krahenbuhl, S.; Fowler, S.; Parrott, N. Construction and verification of physiologically based pharmacokinetic models for four drugs majorly cleared by glucuronidation: Lorazepam, oxazepam, naloxone, and zidovudine. AAPS J. 2020, 22, 128. [CrossRef] [PubMed]

32. Li, S.; Yu, Y.; Bian, X.; Yao, L.; Li, M.; Lou, Y.R.; Yuan, J.; Lin, H.S.; Liu, L.; Han, B.; et al. Prediction of oral hepatotoxic dose of natural products derived from traditional Chinese medicines based on SVM classifier and PBPK modeling. Arch. Toxicol. 2021, 95, 1683-1701. [CrossRef] [PubMed]

33. Docci, L.; Klammers, F.; Ekiciler, A.; Molitor, B.; Umehara, K.; Walter, I.; Krahenbuhl, S.; Parrott, N.; Fowler, S. In vitro to in vivo extrapolation of metabolic clearance for ugt substrates using short-term suspension and long-term co-cultured human hepatocytes. AAPS J. 2020, 22, 131. [CrossRef]

34. Liu, H.; Yu, Y.; Guo, N.; Wang, X.; Han, B.; Xiang, X. Application of Physiologically Based Pharmacokinetic Modeling to Evaluate the Drug-Drug and Drug-Disease Interactions of Apatinib. Front. Pharmacol. 2021, 12, 780937. [CrossRef]

35. Kim, H.J.; Jeong, E.S.; Seo, K.A.; Shin, K.J.; Choi, Y.J.; Lee, S.J.; Ghim, J.L.; Sohn, D.R.; Shin, J.G.; Kim, D.H. Glucuronidation of a sarpogrelate active metabolite is mediated by UDP-glucuronosyltransferases 1A4, 1A9, and 2B4. Drug. Metab. Dispos. 2013, 41, 1529-1537. [CrossRef] [PubMed]

36. Bianco, G.; Pascale, R.; Carbone, C.F.; Acquavia, M.A.; Cataldi, T.R.I.; Schmitt-Kopplin, P.; Buchicchio, A.; Russo, D.; Milella, L. Determination of soyasaponins in Fagioli di Sarconi beans (Phaseolus vulgaris L.) by LC-ESI-FTICR-MS and evaluation of their hypoglycemic activity. Anal. Bioanal. Chem. 2018, 410, 1561-1569. [CrossRef] [PubMed]

37. Ai, L.; Zhu, L.; Yang, L.; Ge, G.; Cao, Y.; Liu, Y.; Fang, Z.; Zhang, Y. Selectivity for inhibition of nilotinib on the catalytic activity of human UDP-glucuronosyltransferases. Xenobiotica 2014, 44, 320-325. [CrossRef] [PubMed]

38. In Vitro Identification of UDP-Glucuronosyltransferases (UGTs) Involved in Drug Metabolism; Johnson \& Johnson Pharmaceutical Research \& Development: Spring House, PA, USA, 2004; Volume 12, pp. 185-202.

39. Sridar, C.; Goosen, T.C.; Kent, U.M.; Williams, J.A.; Hollenberg, P.F. Silybin inactivates cytochromes P450 3A4 and 2C9 and inhibits major hepatic glucuronosyltransferases. Drug Metab. Dispos. 2004, 32, 587-594. [CrossRef]

40. Zhu, L.; Ge, G.; Liu, Y.; He, G.; Liang, S.; Fang, Z.; Dong, P.; Cao, Y.; Yang, L. Potent and selective inhibition of magnolol on catalytic activities of UGT1A7 and 1A9. Xenobiotica 2012, 42, 1001-1008. [CrossRef] [PubMed]

41. Mano, Y.; Usui, T.; Kamimura, H. Inhibitory potential of nonsteroidal anti-inflammatory drugs on UDP-glucuronosyltransferase 2B7 in human liver microsomes. Eur. J. Clin. Pharmacol. 2007, 63, 211-216. [CrossRef] [PubMed] 